\title{
$X X I$. A report of the state of his majesty's flock of finewoolled Spanish sheep during the years 1800 and 1801; with some account of the progress that has been made towards the introduction of that valuable breed into those parts of the United Kingdom where fine clothing wools are grown with advantage
}

Joseph Banks

To cite this article: Joseph Banks (1804) XXI. A report of the state of his majesty's flock of finewoolled Spanish sheep during the years 1800 and 1801; with some account of the progress that has been made towards the introduction of that valuable breed into those parts of the United Kingdom where fine clothing wools are grown with advantage, Philosophical Magazine Series 1, 18:70, 140-145, DOI: 10.1080/14786440408676461

To link to this article: http://dx.doi.org/10.1080/14786440408676461

\section{曲 Published online: 18 May 2009.}

\section{Submit your article to this journal 지}

Џ Article views: 2 
of the sartorius they were six millimetres. The contractions of the straight muscle were very strong, and they were nine millimetres in the two portions of the straight sartorius, which was attached to the respective points. Fitty-nine minutes had elapsed after decapitation, and the experiments were continued on the same parts; and it was not till an hour and twenty-three minutes that they were abandoned. I shall not give any detail respecting them, because they were made in the same manner as the preceding. The results, however, were as follow:-The aorta first ceased to exhibit contractions which were excited by means of the two stimuli before mentioned; the other parts ceased their movements in this order: the intestines, then the left cavities of the heart; the right ventricle and the right auricle the last: after the right auricle, the insulated porion of the sartorius muscle, while the muscles in their places still exhibited very strong contractions. It was then thought useless to continue the experinents, since it was proved that the voluntary muscles were the last to lose their movement.

XXI. A Report of the State of His Majesty's Flock of Finewoolled Spunish Sheep during the Years 1800 and 1801 ; with some Account of the Progress that has been made towards the Introduction of that valualle Breed into those Parts of the United Kingdom where fine Clothing Wools are grown with Advantage.

$\mathrm{O}_{\mathrm{N}}$ the 9 th of June 1800 , when his majesty's Spanish flock was shorn, it consisted of 100 ewes and wethers, which produced as follows :

Wool washed on the sheeps' back - $398 \mathrm{lb}$.

Loss in scouring - $\quad-\quad-104$

Amount of scoured wool $\quad-\quad-\quad 294$

Which produced, when sorted,

$$
\left.\begin{array}{l}
\text { Prime } 234 \mathrm{lb} . \text { at } 5 \mathrm{~s} . \text { per } \mathrm{lb} . \\
\text { Choice 34, } \\
\text { Fribbs } 26, \quad \text { at } 1 \mathrm{~s} .6 \mathrm{~d} .
\end{array}\right\} 651.11 \mathrm{~s} .
$$

Eight rams. and nine ewes were this year disposed of, which were all that could be spared from the flock. Two of the rams went into Dorsetshire, where the breed is much approved by some skilful judges of sheep, and seems likely to produce considerable advantage by crossing with the common sheep of the country. 
Mr. Bridge, of Winford Eagle, communicated this year the result of an experiment he had made on three kinds of sheep; viz. Dorset, half Spanish and half Dorset, and half Spanish and half Mendip.

He kept these sheep from the year 1798, when they were lambed, till February 1800 , when they were butchered as fat sheep; and having valued them in June 1798, he found the carcases of each sort, with two years wool which had been shorn from them, to yield at that time the following increase in value :

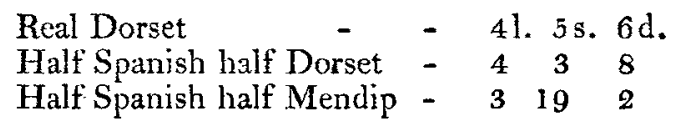

In these experiments Mr. Bridge's woolstapler values the Dorset wool at $1 \mathrm{~s}$. $2 \frac{1}{\mathrm{z}} \mathrm{d}$. a pound, and the half Spanish wool at 1s. $4 \frac{1}{2} \mathrm{~d}$. only; but as the Spanish cross in both cases increased the quantity of wool, and as half Spanish wool has never, when its value was properly known, been sold for less than $1 \mathrm{~s} .9 \mathrm{~d}$. and generally more than $2 \mathrm{~s}$. a pound, there can be no doubt that the improvement in value, arising from the cross, is in both cases considerable.

Mr. J. Ridgeway, of Upperton, in the parish of Yazor, in Herefordshire, communicated an experiment, in which two sheep, the one a Ryeland and the other half Spanish and half Ryeland, of equal weights, were fed by him together: the half Spanish sheep produced in a year $2 \mathrm{lb} .12 \mathrm{oz}$. more wool and $5 \mathrm{lb}$. more mutton than the Ryelander. This gentleman, whom his majesty graciously permitted to have rams from the Spanish flock some years ago, has also shown by his accounts that the wool of his flock, of about 16 score sheep, has been so much increased both in quantity and in value by the Spanish cross, as to have produced nearly twice as much money for each clip after the Spanish blood was established in it, as it usually did before.

In June 1801, the Spanish flock consisted of 108 ewes and wethers,

Which produced in wool, washed on the sheeps' back, $397 \mathrm{lb}$. Loss in scouring - $\quad-\quad-\quad-\quad 112$ Amount of scoured wool $\quad$ - $\quad$ - $\quad 285$

Which produced, when sorted, $\left.\begin{array}{l}\text { Prime } 237 \mathrm{lb} \text {, at } 5 \mathrm{~s} .6 \mathrm{~d} \text {. per lb. } \\ \text { Choice } 31, \quad \begin{array}{l}\text { at } 3 \mathrm{~s} .6 \mathrm{~d} . \\ \text { Fribbs } 17,\end{array}\end{array}\right\} 721.1 \mathrm{~s} .9 \mathrm{~d}$.

The wool of the rams and fatting wethers, which had 
been kept separate, was prepared for sale at the same time, and produced in

$\begin{array}{llc}\text { Wool on the sheeps' back } & - & 220 \mathrm{lb} \text {. } \\ \text { l.ess in scouring } & - & 82 \\ \text { Amount of scoured wool } & - & 138\end{array}$

Which prodaced, when sorted,

$$
\left.\begin{array}{l}
\text { Prime } 96 \mathrm{lb} . \text { at } 5 \mathrm{~s} . \text { per lb. } \\
\text { Choice } 30, \\
\text { Fribbs } 12, \quad \text { at } 1 \mathrm{s.} 6 \mathrm{~d} . \\
\end{array}\right\} 301.6 \mathrm{~d} \text {. }
$$

This year, eight rams and twenty-two ewes were sold. If the foot rot had not unfortunately damaged the rams very materially, more of them would have been disposed of. It is however observable, that although the rams that are kept at Windsor in rich land are occasionally attacked by this harassing distase, the ewes and wethers that feed on the dry and hilly pastures of Oatlands have never been subject to lameness of any kind.

Elcven wethers that had been sent to the marshes in order to try the effect of rich pasture in fattening sheep of this bred, were slaughtered this year by Mr. King, of Newgate Markct, previous to the Smithfield meeting, which usually takes place the week before Christmas. Two of the carcases were given to persons who had been useful in ascertaining the value of the Spanish breed; the remaining nine were sold to Mr. Giblet, butcher, in Bondstreet, whose judgment in selecting, and liberality in purchasing, the best carcases is well known, both to those of whom he buys and to those who buy of him. The sale bill is as follows:

1 Shcep, 6 stone $6 \mathrm{lb}$. at $6 \mathrm{~s}$. per stone $-\quad \begin{array}{lll}2 & 0 & 6\end{array}$

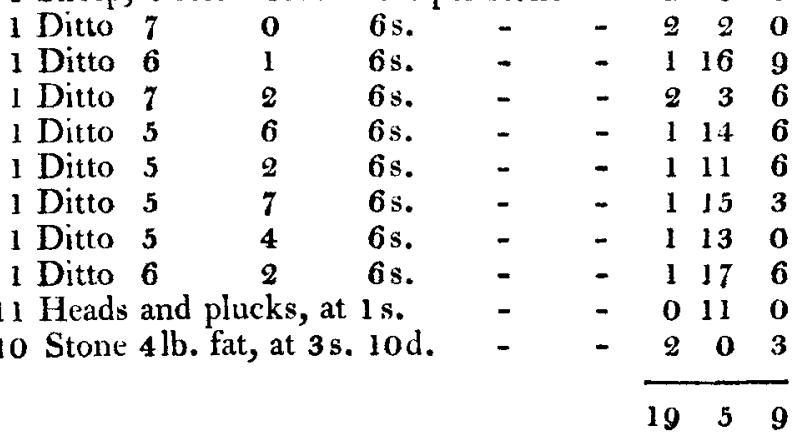

Respecting the goodness of the mutton, inquiry must be made of Mr. Giblet, at whose shop the carcases were shown 
for several days, and of his customers who purchased the joints. Experience has, however, demonstrated already, both at Windsor and at Weybridge, that Spanish mutton is of the best quality for a gentleman's table.

The pelt wool of these eleven sheep was taken off, in order that its value might be ascertained.

$\begin{array}{lcc}\text { It weighed in the yoke } & - & 36 \mathrm{lb} \text {. } \\ \text { Loss in scouring - } & - & 8 \\ \text { Amount of scoured wool } & - & 28\end{array}$

It was sold as skin wool for $4 \mathrm{~s} .6 \mathrm{~d}$. a pound, and of course produced 51. $19 \mathrm{~s}$. or $10 \mathrm{~s}$. a sheep, all expenses deducted. The amount of this profit was quite unexpected, and holds forth a source of advantage in this breed, that has not probably hitherto been calculated upon.

Of all who have laboured to render his majesty's patriotic views in importing Spanish sheep permanently useful to his subjects, Dr. Parry, of Bath, deserves the highest commendation. Amidst the labours of a profession always toilsome when successful, and particularly so at Bath, where persons, whose diseases cannot be ascertained by the faculty elsewhere, continually resort, the doctor found leisure to employ himself in the improvement of the British fleece, by crossing various breeds with Spanish rams presented by his majesty to the marquis of Bath and to the Bath Agricultural Society.

The prizes the doctor has continually obtained from the judicious and respectable body from whom he borrowed rams, for cloths made of his own wool, in the midst of a manufacturing country and amongst abundance of able competitors, prove to a demonstration that he has brought the fleeces of the mixed breed very nearly to the value of the original Spanish; nor is this to be wondered at, when we recollect that the effect of a mixture of breeds operates in the following proportions :

The first cross of a new breed gives to the lamb half of the ram's blood, or -

The second gives - $\quad-\quad$ - 75

The third - - - - $\quad-87 \frac{1}{2}$

The fourth - - - - $-93 \frac{3}{4}$

At which period it is said, that if the ewes have been judiciously selected, the difference of wool between the original stock and the mixed breed is scarcely to be discerned by the most able practitioners.

More need not be said of the doctor's merit: his book, which 
which every man who wishes to improve wool ought to read, will give a more just idea of the acuteness of his discrimination, the diligence with which he pursued his purpose, and the success that finally attended his judicious nimnagement, than can be stated in the brief form of a report like this.

Much, however, as Dr. Parry deserves the gratitude of all who honour the fleece, lord Somerville's merit stands at least as eminently conspicuors. Emulating the example of his sovereign, his lordship, whose just discrimination of the value of different breeds of stock is admitted by the most experienced agriculturists, made a voyage to Portugal for the sole purpose of selecting, by his own judgment, from the bist flocks in Spain, such sheep as joined in the greatest degree the merit of a good carcase to the superiority in wool which the Merino flocks are allowed to possess.

His lordship succeeded, and brought home, more than two years ago, a flock of the first quality, which will probably repay with adtantage the costs of the undertaking, as some of his lordship's rams are said to have been already sold for 100 guineas each.

As ten creps of wool have now been shorn frum his majesty's Spanish flock, and not a single sheep from Spain has been introduced into it during the whole of the ten years that have produced them; and as the tenth crop afforded nearly five-sixths of prime wool and only one-fourteenth of fribbs; it is to be hoped that the deep-rooted prejudice which has for ages deccived the people of England into an opinion that Spanish wool degenerates in this climate, will now be finally lodged in that catalogue of vulgar errors which the increase of human knowledge daily enlarges. It is to be hoped also that a bold assertion hazarded here, that the mutton of Spanish fine-woolled sheep is coarse, tough, and little better than earrion, will be contradicted by the evidence of Mr. Giblet and his customers, to the satisfaction of those who have unwarily given credit to it.

His inajesty having been pleased to permit the sale of such sheep as can be spared from the Spanish flock to be continued, the rams will be delivered at Windsor, and the ewes at Oatlands, in the latter end of August. As, however, it has been suggested to his majesty that the carcases of the sheep are evidently improved, and that the wool has rather gained than lost in value, six guineas will in future be the price of a ram, and two that of an ewe. And as his majesty has been graciously pleased to continue to intrust the management 
nagement of the flock to Sir Joseph Banks, all letters on the subject of it, addressed to him in Soho-square, will be answered, and the utmost endeavours used to consult the convenience of those who wish to become purchasers.

July 2802 .

Joseph Banks.

XXII. Medico-chemical Researches on the Virtues and Principles of Cantharides: extracted from a Memoir of C. Beaupoil by C. Deyeux *.

$T_{\text {hough the animal kingdom affords only a small number }}$ of substances which can be cmployed in medicine, it must still be allowed that among those to which it has recourse, there arc some the effect of which is so certain, so constant, and so striking, that if they were wanting it would be impossible to find others to supply their places.

Cantharides in particular are of this number. Every body know's the manner in which they act, and the resources they afford in a variety of diseases. It needs therefore excite no surprise, that an examination of these insects should at all times have engaged the attention of the most celebrated physicians, and that chemists have often tried to subject them to analysiș.

The principal object of all those who have laboured on cantharides has been to discover whether the vesicant property, which they possess in the highest degree, belongs in general to all the parts of the animal, or whether it does not rather reside in a particular matter, which, independently of those that accompany it, can act alone, and give rise to the effects produced by the whole cantharides.

It would no doubt be superfluous to relate here crery thing which has been done or said on this subject; but it is of importance to remark, that no one before Thouvenel pursued the route which would lead to a solution of the proposed problem : it has been therefore since the period when that physician published the different experiments he made on cantharides, that any hopes have existed of obtaining more accurate knowledge respecting the propertics of the immediate materials of these insects.

However, in rendering justice to the efforts made by Thouvenel, it must be allowed also that he has not carried to a sufficient length the labour which he commenced sa

* From the Annales de Chimie, No. 142.

VoL. XVIII. No. 70. 